Letters addressing topics of current interest or material in RESPIRATORY CARE will be considered for publication. The Editors may accept or decline a letter or edit without changing the author's views. The content of letters reflects the author's opinion or interpretation of information; their publication should not be interpreted as an endorsement by the Journal. Authors of criticized material will have the opportunity to reply in print. No anonymous letters can be published. Letters should be submitted electronically via Manuscript Central. Log onto ReSPIRATORY CARE's web site at http://www.RCJournal.com.

\section{The Stewart Approach for Analysis of Acid-Base Disturbances in Patients With Chronic Respiratory Failure}

We read with great interest the article by Guérin and colleagues, in the November 2010 issue of RESPIRATORY CARE, ${ }^{1}$ describing analysis of acid-base disorders with the Stewart method versus the conventional approach in patients with chronic respiratory failure in stable or unstable respiratory condition. Unfortunately, we find several aspects of the analysis to be rather misleading.

First, according to the Stewart concept ${ }^{2}$ and as Guérin et al clearly explained, the blood $\mathrm{pH}$ depends on 3 independent variables: $\mathrm{P}_{\mathrm{CO}_{2}}$, the strong ion difference (which represents the net balance between strong positive ions and strong negative ions), and the total concentration of nonvolatile weak acids $\left(\mathrm{A}_{\text {tot }}\right)$. As we know, ${ }^{3}$ weak acids, as opposed to strong ions, can exist at physiologic $\mathrm{pH}$ as dissociated $\left(\mathrm{A}^{-}\right)$or associated with a proton $(\mathrm{AH})$ :

$$
\left[\mathrm{A}_{\mathrm{tot}}\right]=\left[\mathrm{A}^{-}\right]+[\mathrm{AH}]
$$

Guérin et al calculated $\left[\mathrm{A}_{\mathrm{tot}}\right]$ with the formula:

$$
\left[\mathrm{A}_{\mathrm{tot}}\right]=\left[\mathrm{albumin}^{-}\right]+\left[\mathrm{Pi}^{-}\right]
$$

Unfortunately, that formula is for $\left[\mathrm{A}^{-}\right]$, not $\left[\mathrm{A}_{\text {tot }}\right]^{.}{ }^{4}$ The correct formula 5 is:

$$
\left[\mathrm{A}_{\mathrm{tot}}\right]=\left[\mathrm{A}^{-}\right]\left[1+10^{(\mathrm{pKa}-\mathrm{pH})}\right]
$$

Second, the techniques Guérin et al used for calcium $\left(\mathrm{Ca}^{2+}\right)$ and magnesium $\left(\mathrm{Mg}^{2+}\right)$ measurements give total concentrations. Hence, the ionized portions of $\mathrm{Ca}^{2+}$ and $\mathrm{Mg}^{2+}$ were not used to calculate the apparent strong ion difference, as is recommended. ${ }^{6}$ Thus, the apparent strong ion difference values, and therefore those of the strong ion gap, provided by Guérin et al are not quite correct. Consequently, the correction of these values could influence the study results. On the other hand, it is confusing that they used 2 variables ("unidentified strong anions" [XA] and strong ion gap) that belong to the same approach to quantify the unmeasured anions. Indeed, as Guérin et al provided the lactate concentration values, the determination of XA $([\mathrm{XA}]=[$ strong ion gap $]+[$ lactate $])$ had a little interest. Note also that lactate is not considered "unmeasured," and the strong ion gap not only detects the presence of unmeasured strong ions but also unmeasured weak ions. 3,7

Third, the standard base excess formula used to diagnose acid-base status according to what Guérin et al called "the conventional approach" (see their Equation 4) is the corrected standard base excess equation that updates the base excess to allow for change in $\mathrm{A}_{\text {tot }} \cdot{ }^{6}$ Therefore, that standard base excess, as used in the study, does not belong to the conventional approach. Actually, the study did not compare the Stewart method to the conventional approach, but to more traditional ones, improved by the use of corrected standard base excess. Kellum ${ }^{6}$ called this a semi-quantitative approach in the reunification of acid-base physiology. We also think that the data presented cannot be used to assess the value of the Stewart method, since the calculations of $\mathrm{A}_{\text {tot }}$, apparent strong ion difference, and strong ion gap are in error.

Jihad Mallat MD Didier Thevenin MD

Service de Réanimation Polyvalente Centre Hospitalier Dr Schaffner de Lens Lens, France

The authors have disclosed no conflicts of interest.

\section{REFERENCES}

1. Guérin C, Nesme P, Leray V, Wallet F, Bourdin G, Bayle F, et al. Quantitative analysis of acid-base disorders in patients with chronic respiratory failure in stable or unstable respiratory condition. Respir Care 2010;55(11):1453-1463.

2. Stewart PA. Modern quantitative acid-base chemistry. Can J Physiol Pharmacol 1983; 61(12):1444-1461.

3. Kellum JA. Disorders of acid-base balance. Crit Care Med 2007;35(11):2630-2636.
4. Figge J, Rossing TH, Fencel V. The role of serum proteins in acid-base equilibria. J Lab Clin Med 1991;117(6):453-467.

5. Constable PD. Total weak acid concentration and effective dissociation constant of nonvolatile buffers in human plasma. J Appl Physiol 2001;91(3):1364-1371.

6. Kellum JA. Clinical review: reunification of acid-base physiology. Crit Care 2005; 9(5):500-507.

7. Kellum JA, Kramer DJ, Pinsky MR. Strong ion gap: a methodology for exploring unexplained anions. J Crit Care 1995;10(2): 51-55.

\section{The author responds:}

We thank Drs Mallat and Thevenin for their comments. Their points are well taken and correct, and we would like to address each of them.

First, it is true that the way we used $\mathrm{A}_{\text {tot }}$ applies for $\mathrm{A}^{-}$and not $\mathrm{A}_{\text {tot }}$. However, computing $\mathrm{A}_{\text {tot }}$ as $\left[\mathrm{A}^{-}\right]\left[1+10^{(\mathrm{pKa}-\mathrm{pH})}\right]$ in our data $^{1}$ by taking the value of 6.12 for $\mathrm{pHa}^{2}$ resulted in a minor difference (Fig. 1). The bias amounted to $0.57 \mathrm{mmol} / \mathrm{L}$.

Second, it is true that we measured total plasma calcium and magnesium instead of their ionized counterparts. We agree that it is not correct to use the total concentration (free + protein-bound) of some ions in the apparent-strong-ion-difference equation. It is, however, unlikely that this would markedly change the value of the apparent strong ion difference. The weight of calcium and magnesium in the apparent strong ion difference is low, and some authors simplified the computation of apparent strong ion difference toward the difference between $\mathrm{Na}^{+}$and $\mathrm{Cl}^{-} .{ }^{3}$ Constable and Stämpfli ${ }^{2}$ stressed that accurate measurement of apparent strong ion difference in human plasma may be difficult, and computed it via 3 formulae:

$$
\begin{aligned}
& \left(\mathrm{Na}^{+}+\mathrm{K}^{+}\right)-\left(\mathrm{Cl}^{-}\right)\left(\mathrm{Na}^{+}+\mathrm{K}^{+}\right) \\
& -\left(\mathrm{Cl}^{-}+\text {lactate }\right)\left(\mathrm{Na}^{+}+\mathrm{K}^{+}\right. \\
& \left.+\mathrm{Ca}^{++}+\mathrm{Mg}^{++}\right)-\left(\mathrm{Cl}^{-}+\text {lactate }\right)
\end{aligned}
$$

The corresponding mean \pm SD values of the apparent strong ion difference in the ve- 


\section{LETTERS TO THE EDITOR}

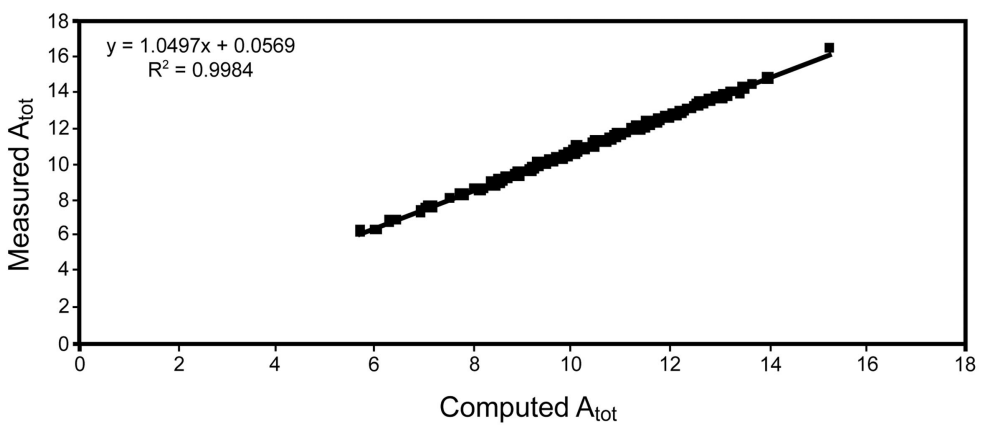

Fig. 1. Relationships between the original values of total concentration of nonvolatile weak acids $\left(A_{\text {tot }}\right)$ and the $A_{\text {tot }}$ values computed from the equation $A_{\text {tot }}=\left[A^{-}\right]\left[1+10^{(\mathrm{pKa}-\mathrm{pH})}\right]$.

nous blood of 8 humans (see Table 2 in reference 2) were $40.9 \pm 2.9 \mathrm{mEq} / \mathrm{L}$, $40.0 \pm 2.9 \mathrm{mEq} / \mathrm{L}$, and $43.0 \pm 2.9 \mathrm{mEq} / \mathrm{L}$, respectively. The measurements were on normal plasma and did not pertain to patients. Furthermore, the amount of calcium electrostatically bound to plasma protein is $0.8 \mathrm{mmol}$, as compared to $36 \mathrm{mmol}$ for $\mathrm{Na}^{+} .2$

We presented unidentified strong anions (XA) and strong ion gap not to confuse the reader but because we found it interesting to describe these 2 ways to bridge the gap between the various measured ions.
Third, you are correct in that the standard base excess is an update of the conventional approach, and it would have been more appropriate to read it as such.

Finally, we stress that, even though our computations of $\mathrm{A}_{\text {tot }}$, apparent strong ion curate (strong ion gap was not correct because apparent strong ion difference was not), it remains that the values of the effective strong ion difference were correct in our study. Therefore, in our study the comparisons between the 4 chronic-respiratorydifference, and strong ion gap were not ac- failure groups were correct on that basis, as was the distinction between the acid-base disorders categories from the Stewart approach.

Claude Guérin MD PhD

Service de Réanimation Médicale et

d'Assistance Respiratoire Hôpital de la Croix Rousse Lyon, France

The author has disclosed no conflicts of interest.

\section{REFERENCES}

1. Guérin C, Nesme P, Leray V, Wallet F, Bourdin G, Bayle F, et al. Quantitative analysis of acid-base disorders in patients with chronic respiratory failure in stable or unstable respiratory condition. Respir Care 2010;55(11):1453-1463.

2. Constable PD, Stämpfli HR. Experimental determination of net protein charge and $\mathrm{A}(\mathrm{tot})$ and $\mathrm{K}(\mathrm{a})$ of nonvolatile buffers in canine plasma. J Appl Physiol 2005; 19(4)507-514.

3. Story DA. The Fencl-Stewart acid-base concept: a clinical guide. International J Int Care 2006:19-22. 